\title{
Affective Inhibitory Control and Risk for Internalizing Problems in Adolescents Exposed to Physical and Psychological Abuse.
}

\section{A Population-based Study}

\author{
Sjur S. Sætren
}

CAMHS Sola, Division of Psychiatry, Stavanger University Hospital, Norway.

Else-Marie Augusti

Norwegian Centre for Violence and Traumatic Stress Studies, Department for Child and Adolescent Research, Norway.

\section{Gertrud Sofie Hafstad}

Norwegian Centre for Violence and Traumatic Stress Studies, Department for Child and Adolescent Research, Norway.

Corresponding author:

Sjur Skjørshammer Sætren, Msc

CAMHS Sola, Division of Psychiatry, Stavanger University Hospital, Norway

Kreklingvegen 15, 4054 Raege

sjursaetren@gmail.com

Telephone: +4792809458

Word count: 5628 


\begin{abstract}
Background. Adolescents' emotion regulatory capacities may modulate the relationship between childhood maltreatment experiences and psychopathology. Affective inhibitory control constitutes an important part of emotion regulation and involves the ability to regulate automatic or prepotent responses to irrelevant and potentially distracting emotional information. Aims. The aim of the present study was to investigate the role of affective inhibitory control in the relationship between exposure to childhood psychological and physical abuse and internalizing problems in adolescence. Method. A nationally representative sample of adolescents ( $\mathrm{Mage}_{\mathrm{SD}} \mathrm{S}=14 / .8$ ) exposed to physical and psychological abuse $(N=1841 ;$ male $=964 ;$ female $=877)$ conducted an Emotional Go/No-go task Participants were presented with angry facial expressions as emotional no-go stimuli in order to examine their ability to inhibit behavioral responses to threatening task-irrelevant stimuli.

Results. Affective inhibitory control problems were uniquely related to internalizing problems in girls, but not in boys. Moreover, affective inhibitory control moderated the relationship between exposure to psychological abuse and internalizing problems in girls. We did not observe any relationship between inhibitory control and internalizing problems when neutral faces were presented as task-irrelevant information. Conclusion. Findings suggest that a reduced ability to inhibit threatening, but task-irrelevant, information is related to internalizing problems in adolescent girls exposed to physical and psychological abuse. This highlights the importance of affective inhibitory control as a potential moderating mechanism in individual risk for experiencing internalizing problems in abused adolescent girls.
\end{abstract}

Keywords: Inhibitory control, emotion regulation, child maltreatment, internalizing psychopathology, adolescents.

\title{
General Scientific Summary
}

This study suggests that the ability to regulate, or inhibit, responses to task-irrelevant threatening information is an important risk factor for internalizing symptoms following exposure to childhood abuse. Adolescent girls with greater regulatory problems are at substantially greater risk of experiencing internalizing symptoms compared to those who regulate their responses to threatening information more efficiently. 


\section{Introduction}

Children living in an abusive family context are at greater risk for a wide range of internalizing problems, which often persist into adulthood (Jaffee, 2017). In fact, it has been estimated that up to 59 percent of depression and anxiety cases worldwide may be attributed to child maltreatment (Li, D'arcy, \& Meng, 2016). The onset of anxiety and mood disorders peaks during adolescence, when girls in particular are at greater risk of developing depression and anxiety (Hayward \& Sanborn, 2002; Zahn-Waxler, Shirtcliff, \& Marceau, 2008). Adolescence is a developmental period characterized by heightened emotional reactivity and increased sensitivity to emotional stimuli (Casey, 2015). This heightened risk for negative emotionality and poor outcomes is suggested to be due, in part, to a lack of emotion regulation capacity and intensified reactivity during youth (Kelley, Schochet, \& Landry, 2004). A number of neurobiological models support this notion, suggesting an imbalance in neural activity that is reflected in differential age-specific development of the prefrontal cortical and limbic subcortical circuits (Casey, Jones, \& Hare, 2008; Ernst, 2014; Steinberg, 2008).

However, there is great individual variation in mental health outcomes among those exposed to abuse, and some individuals are more susceptible to the negative impact associated with such adversity (Cicchetti, 2016). Researchers have proposed several potential mechanisms involved in emotion processing and regulation that may modulate the effect of stress posed by an abusive environment on internalzing symptoms (Cicchetti, 2016; Jaffee, 2017). Given the great variation in individual responses to environment, the regulation of emotional responses may either increase or reduce the risk of psychopathology following child maltreatment (Dvir, Ford, Hill, \& Frazier, 2014).

\section{Affective Inhibitory Control as an Index of Emotional Dysregulation}

Research suggests that emotion regulation is a transdiagnostic process across psychopathologies (Aldao, 2012; Aldao, Gee, De Los Reyes, \& Seager, 2016; Fernandez, Jazaieri, \& Gross, 2016). Children with low emotion regulatory capacities are at greater risk of developing psychopathology following child maltreatment (Cicchetti, 2016; Dvir et al., 2014; Kim \& Cicchetti, 2010), whereas more efficient and adaptive regulation is associated with resilience (Kim \& Cicchetti, 2010; Sætren, Sütterlin, Lugo, Makransky, \& PrinceEmbury, 2019).

A central mechanism in adolescents' top-down regulation of bottom-up emotional reactivity is affective control, consisting of inhibiting responses, updating, and shift of 
attention (Schweizer, Gotlib, \& Blakemore, 2020). Inhibitory control reflects the ability to withhold automatic responses to irrelevant and potentially distractive stimuli (Casey, Tottenham, \& Fossella, 2002). Within an emotional context, this ability is regarded as a hallmark of successful regulation (Hofmann, Schmeichel, \& Baddeley, 2012), and is found to be associated with emotion regulation across age groups (Ahmed, Bittencourt-Hewitt, \& Sebastian, 2015; Schweizer, Parker, Leung, Griffin, \& Blakemore, 2020; Tottenham, Hare, \& Casey, 2011). We therefore refer to inhibitory control within an emotional context as affective inhibitory control.

Growing evidence suggests an association between reduced inhibitory control functions and psychopathology following trauma (Aupperle, Melrose, Stein, \& Paulus, 2012). The ability to effectively disengage from emotional stimuli may, on the other hand, contribute to resilience in the face of such adversity (Aupperle et al., 2012). With regard to internalizing symptoms, problems with attention regulation and response inhibition (i.e., inhibitory control) are considered to be cognitive vulnerabilities in adolescents, especially in girls (Davis, Miernicki, Telzer, \& Rudolph, 2019; Han et al., 2012; Joormann \& Gotlib, 2010; Susa, Pitică, Benga, \& Miclea, 2012; Waters, Valvoi, \& Psychiatry, 2009). Research suggests that this also may apply to children exposed to child maltreatment (Pollak, 2008). However, the majority of research on emotion processing and regulation in maltreated children is conducted in experimental settings or with small sample sizes. Furthermore, the role of affective inhibitory control in maltreated children's adaptive/maladaptive reactions has not yet been explored. Some evidence suggests that dysregulation of attention towards threat cues in non-threatening environments, and problems with disengagement from such information, is related to increased anxiety in abused children (Pollak, Cicchetti, Hornung, \& Reed, 2000; Pollak \& Kistler, 2002; Pollak, Messner, Kistler, \& Cohn, 2009; Pollak \& Sinha, 2002; Schweizer, Parker, et al., 2020; Shackman, Shackman, \& Pollak, 2007). Reduced inhibitory functions may increase maladaptive rumination (Yang, Cao, Shields, Teng, \& Liu, 2017). Biological evidence shows that adolescents at risk for depression and anxiety experience hyperactivation in the amygdala when exposed to fearful or angry facial expressions (Monk et al., 2008). Preliminarily findings also suggest that cognitive control training may lead to a reduction in post-traumatic symptoms, and increased recruitment of adaptive emotion regulation strategies (Schweizer et al., 2017). In line with this, an increasing number of studies suggest that emotion regulation modulates the relationship between child maltreatment exposure and the 
risk of internalizing problems (e.g., Jennissen, Holl, Mai, Wolff, \& Barnow, 2016; Peh et al., 2017).

An important next step for research on the role of inhibitory control in the relationship between child maltreatment and development of internalizing problems during youth is to investigate the relationship in larger and more representative samples. Until recently, this has been methodologically challenging.

\section{The Present Study}

The present study aimed to investigate whether affective inhibitory control is related to individual variations in adolescents' risk for internalizing symptoms when exposed to physical and/or psychological abuse. The following hypotheses were tested: (1) affective inhibitory control will uniquely explain variance in internalizing problems when accounting for the effect of physical and psychological child maltreatment; and (2) affective inhibitory control will moderate associations between physical and/or psychological child maltreatment and internalizing problems in adolescents.

Previous studies of emotion processing and regulation in maltreated samples have mainly investigated physical abuse. However, physical abuse often co-occurs alongside psychological abuse, also known as emotional abuse (Taillieu, Brownridge, Sareen, \& Afifi, 2016). Psychological abuse refers to threatening verbal or non-physical behavior towards a child that may result in potential or actual threat, discrimination, or ridicule (Gilbert et al., 2009; Krug, Mercy, Dahlberg, \& Zwi, 2002) (Stoltenborgh, Bakermans-Kranenburg, Alink, $\&$ van IJzendoorn, 2012). The two forms of abuse share one important characteristic (i.e., fear of being physically attacked). Therefore, we wanted to extend the scope of the present study to investigate affective inhibitory control in a sample of both physically and psychologically abused adolescents. To our knowledge, psychological abuse has not been studied in relation to affective inhibitory control and internalizing problems.

The existing literature suggests that cognitive control within emotional contexts is important for adolescents' emotion regulation (Ahmed et al., 2015; Tottenham et al., 2011), and that reduced affective inhibitory capacities may serve as a significant risk factor for internalizing problems in abused individuals. It further suggests that affective inhibitory control may modulate the relationship between exposure to child maltreatment and internalizing problems. 


\section{Method}

\section{Sample}

The current data is a subsample drawn from the Norwegian Youth Study on Child Maltreatment (The UEVO study), a large-scale, nationwide, web-based survey of adolescents' exposure to child maltreatment (for cohort profile, see Hafstad, Sætren, Myhre, BergerudWichstrøm \& Augusti, 2020, forthcoming). Through stratified sampling, adolescents were recruited from a representative sample of schools in Norway. The subsample in the present study was drawn and selected from the total sample of 9240 12- to 16-year-olds (total survey response rate $=86.7 \%$ ), based on reports of either physical or psychological abuse during childhood. The final sample then included 1841 adolescents (Mage/SD = 14 years/.8; 964 males; 877 females), of which the vast majority were born in Norway (89.6\%). In this group, 872 of the selected adolescents (507 males; 358 females) reported one or more occurrences of physical abuse (missing, $n=4$ ), while 1603 (798 males; 792 females) reported one or more occurrences of psychological abuse (missing, $n=2$ ). In addition, 1486 completed the emotional Go/No-go task (males $=742$; females 733; missing $=371$ ). Participants that completed the survey on tablets (not PCs) could not complete the go/no-go task, which may explain the relatively greater amount of missing data on this task.

\section{Study Ethics}

The UEVO study was approved by the Regional Committee for Medical and Health Research Ethics in Norway (Case \# 2018/522), and is the first large-scale study in Norway in which children from 12 years of age were allowed to consent to participation independent of their parents when investigating child maltreatment. In accordance with article 12 of the UNCRC (Unicef, 1989), stating that children and adolescents have the right to be heard, the Act on Medical and Health Research in Norway (Helseforskningsloven, 2008) has recently passed a regulation allowing children between twelve and sixteen years of age to participate in research without a parent's informed consent, in cases where a conflict of interest between the parent and child may hinder the child's research participation.

\section{Procedure}

Data collection was conducted through a secure web-based survey during school hours within a restricted time period. To ensure correct understanding of the assessment procedure and to increase participants' motivation, they were first shown a short video animation tailored to the present study. The survey comprised four parts, of which the first three consisted of self-reported measures covering; 1) demographic information, 2) history of 
exposure to child maltreatment, and 3) mental health. The fourth part included a selfadministered cognitive task embedded in the survey format, completed via PC. We used the Emotional Go/No-go paradigm to assess response inhibition.

\section{Materials and Measures}

\section{Child Maltreatment}

Participants' history of child maltreatment exposure was assessed by items mapping experiences of physical and psychological abuse that were culturally adapted to the target age group. Item selection was inspired by the Parent-Child Conflict Tactics Scales (Straus, Hamby, Finkelhor, Moore, \& Runyan, 1998), and is comparable with that of previous prevalence studies on child abuse in Norway (Mossige \& Stefansen, 2007, 2016), and Sweden (Janson, 2001; Janson, Långberg, \& Svensson, 2007; Jernbro \& Janson, 2017; Jernbro, Otterman, Lucas, Tindberg, \& Janson, 2017; Jernbro, Svensson, Tindberg, \& Janson, 2012). This was done to ensure comparability to other studies and the possibility for replication.

Physical and psychological abuse were measured by six and eight items, respectively, presented on a four-point scale: 0 (never), 1 (once), 2 (sometimes), and 3 (often). Responses are summarized as a total index score, where higher scores on each scale indicate greater exposure to abuse. Specific items describe various forms of physical and psychological abuse conducted by one or more adults living with the child. The physical abuse scale yielded an alpha on .833 for the total sample and $=.750$ for the maltreated sample. For the psychological abuse scale, the alpha was $=.792$ for the total sample and .627 for the maltreated group.

\section{Internalizing Problems}

The Hopkins Symptom Checklist-10 (HSCL-10) was used to assess youths' internalizing problems. Each item is presented on a four-point scale, ranging from 'Not at all' and 'A little' to 'Quite a bit' and 'Extremely'. A valid cut-off value for the prediction of clinical mental distress is estimated to be an average score $\geq 1.60$ (Haavet, Sirpal, Haugen, \& Christensen, 2010). The scale is validated for the screening of internalizing symptoms in adolescents between the ages of 14 and 16 years in Norwegian primary care institutions (Haavet et al., 2010). In the present study, only nine of the ten items were used, as one item ("Feeling everything is an effort") was lost during web-survey construction. Psychometric evaluation of the scale consisting of nine of ten items revealed high Cronbach's alphas (total sample $=.915$; maltreated sample $=.899$ ). The scale has previously been shown to be valid with both five and six items (Christensen, Haugen, Sirpal, \& Haavet, 2015; Haavet et al., 2010; Strand, Dalgard, Tambs, \& Rognerud, 2003). 


\section{Affective Inhibitory Control}

The Emotional Go/No-go task (Hare et al., 2008) was used as a behavioral task to measure response inhibition within the context of threatening information. The Emotional Go/No-go paradigm was programmed in Java and presented as a self-administered, online-based, cognitive task, and responses were collected by Conexus software (https://conexus.net/). Participants were instructed to complete two blocks of the emotional Go/No-go task using neutral and angry facial expressions as target and non-target stimuli (neutral/angry and angry/neutral). The order of target and non-target stimuli was pseudo-randomized across the run for all subjects to control for order of presentation. Participants were told that different faces would be presented, and asked to respond as quickly as was possible without making mistakes to the target expression (go trails) by pressing the "spacebar" while withholding (i.e., inhibit) their response to the other expression (no-go trails). The target and non-target stimuli (neutral/angry facial expression) were always presented in the center of the screen, and a center-point (+) was shown prior to each stimuli presentation to guide subjects to focus on the center of the screen during assessment. There was a disproportionately higher number of go trials (70/30 ratio) in order to ensure that participants' predominant reaction was to respond. In this way, participants' performance was automated. Duration of stimuli presentation was 500 milliseconds with an inter-stimulus interval varying randomly between 1250 and 1750 milliseconds (see Figure 1 for visual illustration). Each block consisted of 32 trials (22 go trails and 10 no-go trails), and participants were not given any information regarding the disproportionate stimuli presentation or the combination of target and non-target stimuli which would be presented first. Each participant sat alone in a quit classroom during assessment. 


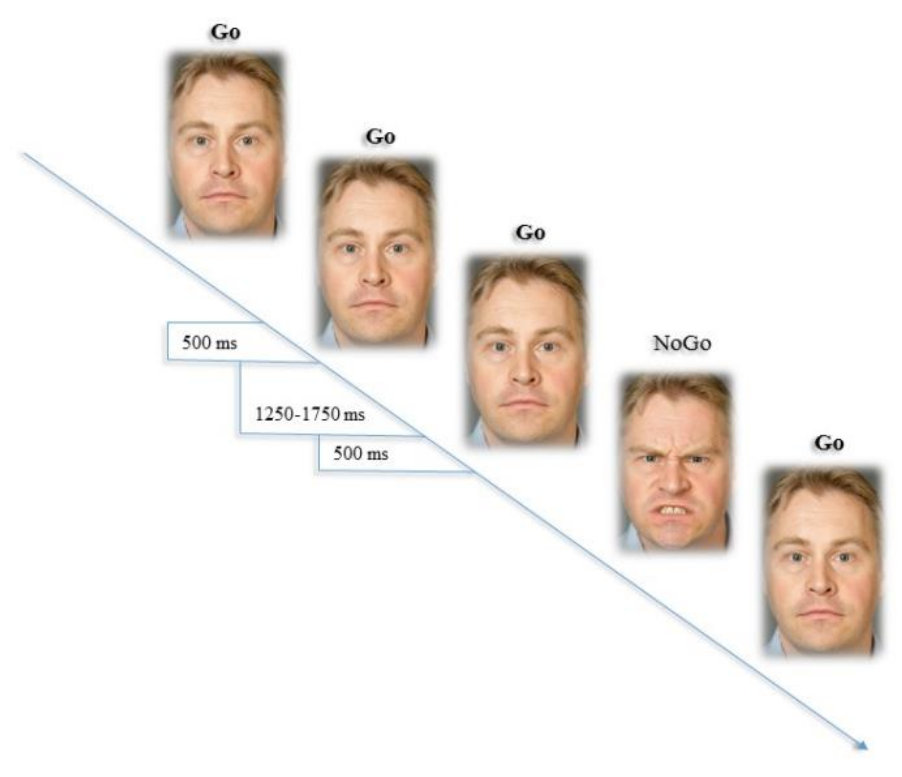

Figure 1. Visual illustration of stimulus presentation in the Emotional Go/No-go task.

The basic constructs of the original Go/-No-go task have been found to be preserved in emotional adaptation, in addition to offering a valid index of behavioral inhibition in emotionally eliciting conditions (Schulz et al., 2007). Task performance has also been found to reflect emotional processing (Schulz et al., 2007) and to capture important components of emotion regulation supported by neurobiological correlates (Hare et al., 2008). The task has been used as an objective behavioral index of emotion regulation across age groups (Tottenham et al., 2011). Together, the evidence supports the construct validity of the emotional Go/No-go task.

\section{Stimuli and Apparatus}

Facial expression stimuli were selected from the Umeå University Database of Facial Expressions (Samuelsson, Jarnvik, Henningsson, Andersson, \& Carlbring, 2012). Through their online-based validation study, they developed a database containing 424 color images of facial expressions that can be freely used by the scientific community. It consists of 60 multiethnic models (30 male/30 female) aged 17 to 67 years showing seven different facial expressions (angry, surprised, happy, sad, fearful, disgusted, and neutral). Overall, mean proportion of correctly interpreted facial expressions is found to be $88 \%$ for this database (Samuelsson et al., 2012), compared to $79 \%$ for the widely used NimStim database (Tottenham et al., 2009). In the present study, a subset of neutral and angry facial stimuli was selected based on its relevance for research questions regarding traumatized adolescents (cf. 
Pollak, 2008; Pollak et al., 2000; Shackman et al., 2007). The validity (proportion interpreted correctly) of the facial images determined further selection of neutral and angry stimuli. Higher image validity reduces error variance in subjects' perception, thereby increasing the reliability of the assessment. It also increases the probability that participants' task performance will actually reflect the effect of the emotional condition, namely anger, as an indication of threat. A neutral stimulus is crucial for the investigation of how emotional valence may affect inhibition performance.

\section{Data Analyses}

In the analysis and examination of the Emotional Go/No-go task performance indicating inhibitory control, we conducted calculations of false alarm rates (also known as commission errors) to determine the proportion of total possible errors for the given condition.

Participants' inhibitory performance when neutral facial expressions were presented as taskirrelevant information (i.e., False Alarm (FA) Neutral) indicates inhibitory control.

Participants' errors in inhibiting their responses when angry facial expressions were presented as task-irrelevant information (i.e., False Alarm (FA) Angry) were used as an indication of affective inhibitory control. Previous studies have used and interpreted this behavior as an indication of emotional dysregulation (Ahmed et al., 2015; Hare et al., 2008; Tottenham et al., 2011).

Two hierarchical multiple regression analyses, including age, physical abuse, and psychological abuse, were entered in the first step for both analyses, with inhibitory control with neutral distractor (FA neutral) in the second step for the first analysis and inhibitory control with angry stimuli as distractor (FA angry) for the second analysis. We conducted these analyses separately for boys and girls. A bootstrapping test was conducted in order to account for potential bias within the results.

To investigate whether inhibitory control moderated the relationship between child maltreatment (physical and/or psychological) and internalizing problems (HSCL total score), we conducted a linear regression model in order to investigate interaction effects (i.e., moderation) by creating an interaction term for independent variables (computation $=$ inhibitory control*child maltreatment). The interaction variable was entered in the linear regression model together with both explanatory variables (i.e., inhibitory control and physical/psychological abuse). We conducted simple slope analysis for the moderation effect in order to test the interaction effect on three different levels of affective inhibitory control problems. Instead of using +/- 1 standard deviation from the mean, the three levels were 
selected by visually evaluating the distribution in order to reflect adolescents with low, medium, and high rates of commission errors: 10 percent, 18 percent, and 30 percent FA angry. A total of fifty percent commission error was possible under the angry facial expression condition as the remaining fifty percent was under a neutral facial expression condition. In other words, we wanted to discover whether the effect of the explanatory variable on the criterion variable varied depending on the level of the moderation variable (i.e., affective inhibitory control).

The statistical analyses were conducted using SPSS version 25 (version 25, IBM, 2017). Because the 25th version of SPSS has trouble running the bootstrapping test application for hierarchical regression modeling, this was done using $R$ Project for Statistical Computing (R.C.Team, 2019). Lastly, in line with the recent discussion of $p$-value interpretation in the paper "Moving to a World Beyond " $p<0.05$ "” (Wasserstein, Schirm, \& Lazar, 2019), the results in the present study will be interpreted in light of its context together with prior knowledge and research within the field of inhibitory control and child maltreatment (VachaHaase \& Thompson, 2004).

\section{Results}

\section{Description of the Sample}

Table 1 summarizes the descriptive statistics for all variables and results from gender comparisons. Initial analyses revealed gender effects for several variables. There were significant gender differences in internalizing problems (i.e., HSCL mean score), as well as in neutral inhibitory control (i.e., FA neutral) and affective inhibitory control (i.e., FA angry). Together, this supports our decision to conduct all analyses separately for each gender. Participants' mean inhibition performance is comparable to data that has been reported in previous validation studies of the emotional Go/No-go task (Schulz et al., 2007).

As expected, several of the included variables were substantially skewed due to the epidemiological nature of the present study, including physical and psychological child maltreatment scales, and, to some extent, the HSCL-10 scale. Variables were not transformed as their distribution was indicative of relatively low rates of abuse and depressive symptoms. In addition, as the current sample is considered to be representative of adolescents in Norway, the distributions of these variables are expected to reflect the real population.

Table 1. Descriptive statistics for age, type of child maltreatment, cognitive control variables, and internalizing symptoms. 


\begin{tabular}{llll}
\hline & Boys & Girls & \\
& $N=964(51.9 \%)$ & $N=877(47.2 \%)$ & Group comparisons \\
\hline Age Mean/SD & $14.5 / .87$ & $14.5 / .87$ & - \\
$\begin{array}{l}\text { Psychological CM (0 - 3) } \\
\text { Mean (SD) }\end{array}$ & $.35(.38)$ & $.37(.36)$ & \\
Physical CM (0 -3) & & & \\
Mean (SD) & $.22(.39)$ & $.17(.33)$ & \\
Inhibitory Control & $(n=742)$ & $(n=733)$ & $t(1466)=-2.91, p<.004$ \\
False Alarm Neutral \% (SD) & $15.94(13.79)$ & $13.92(12.74)$ & $t(1473)=-3.81, p<.001$ \\
False Alarm Angry \% (SD) & $23.34(15.18)$ & $20.36(14.82)$ & \\
Internalizing Symptoms (0 - 3) & $(n=946)$ & $(n=872)$ & $t(1692)=13.22, p<.001$ \\
HSCL-10 mean score (SD) & $0.54(.59)$ & $0.95(.76)$ & \\
\hline
\end{tabular}

Note. Abbreviations: $M=$ mean, $\mathrm{SD}=$ standard deviation. HSCL-10 = Hopkins Symptom Checklist.

\section{The Explanatory Power of Affective Inhibitory Control in Adolescents' Internalizing Problems}

In the first step of both analyses, we found that psychological child maltreatment predicted internalizing problems in female adolescents $(p<.001)$ when accounting for the effect of physical child maltreatment and age (see Table 2a). This indicates that exposure to psychological abuse is related to increased self-reported internalizing symptoms in girls. When neutral inhibitory control (i.e., FA neutral) is included in step two, the coefficients of psychological child maltreatment are approximately the same, but inhibitory control does not significantly explain variance in internalizing symptoms in girls $(p<.295)$ when accounting for the effect of the other variables. When affective inhibitory control (FA angry) was entered in step two in the analysis, results also indicated a unique prediction of internalizing problems in girls $(p<.001)$. It also results in an increment in the total model's prediction $(\Delta R 2=.014, p$ $<.001 ; F(4.725)=18.352, p<.001)$, explaining about nine percent of internalizing problems in maltreated girls. In line with the first hypothesis, this indicates that affective inhibitory control is related to greater internalizing problems in abused girls. In order to investigate whether deviations from the parametric assumptions of the regression model (i.e., heteroscedasticity and non-normality in the data) influenced the current data, a bootstrap regression model with 10000 replications was conducted for the regression analyses. The confidence intervals and standard error of unstandardized regression coefficients remained approximately the same. For psychological child maltreatment, there was a small but insignificant increase in the standard error of the unstandardized regression coefficient $(S E=$ .104). Together, it indicates that results were not biased because of assumption deviations. 
For the boys, results from regression analyses revealed that neither neutral nor affective inhibitory control (FA neutral and FA angry) uniquely predicted internalizing problems when accounting for the effect of age and psychological and physical abuse (FA neutral: $B=-.001$, $S E=.002, \beta=-.014, p=.680 ;$ FA angry: $B=.000, S E=.001, \beta=-.003, p=.935)$.

Table 2. Summary of Hierarchical Multiple Regression Analyses predicting internalizing symptoms in girls; in Table $2 a$, neutral inhibitory control is entered in step 2, and in Table $2 b$, affective inhibitory control is entered in step 2.

Table $2 a$

Table $2 b$

\begin{tabular}{|c|c|c|c|c|c|c|c|c|c|}
\hline$n=730$ & $B$ & $S E$ & $\beta$ & $P$ & $n=730$ & $B$ & $S E$ & $\beta$ & $P$ \\
\hline Step 1 & & & & & Step 1 & & & & \\
\hline Age & $.039(-.020-.097)$ & .030 & .046 & .197 & Age & $.039(-.020-.097)$ & .030 & .046 & .197 \\
\hline Psych CM & $.500(.349-.651)$ & .077 & .251 & .000 & Psych CM & $.500(.349-651)$ & .077 & .251 & .000 \\
\hline Physic CM & $.124(-.059-.306)$ & .093 & .052 & .183 & Physic CM & $.124(-.059-.306)$ & .093 & .052 & .183 \\
\hline Step 2 & & & & & Step 2 & & & & \\
\hline Age & $.052(-.007-.111)$ & .030 & .062 & .086 & Age & $.051(-.008-.109)$ & .030 & .060 & .092 \\
\hline Psych CM & $.486(.336-637)$ & .077 & .244 & .000 & Psych CM & $.494(.344-644)$ & .076 & .248 & .000 \\
\hline Physic CM & $.113(-.068-.294)$ & .092 & .047 & .222 & Physic CM & $.103(-.078-.284)$ & .092 & .043 & .265 \\
\hline \multirow[t]{2}{*}{ FA Neutral } & $.002(-.002-.006)$ & .002 & .038 & .295 & FA Angry & $.006(.002-.009)$ & .002 & .118 & .001 \\
\hline & Adjusted $R_{2}$ & $\Delta R_{2}$ & & & & Adjusted $R_{2}$ & $\Delta R_{2}$ & & \\
\hline Model 1 & .075 & & & .000 & Model 1 & .075 & & & .000 \\
\hline Model 2 & .075 & .001 & & .295 & Model 2 & .087 & .014 & & .000 \\
\hline
\end{tabular}

Note. Two-tailed 95\% confidence intervals in parentheses. FA Neutral = false alarm neutral, FA angry = false alarm angry, Psych CM = psychological child maltreatment, Physic CM = physical child maltreatment, HSCL$10=$ Hopkins Symptom Checklist.

\section{Moderation Effect of Affective Inhibitory Control in the Relationship between Psychological Abuse and Internalizing Problems in Girls}

A moderation analysis was conducted to test the second hypothesis that affective inhibitory control problems (FA angry) moderate the relationship between physical and/or psychological child maltreatment and internalizing problems in abused adolescents. Results (see Figure 2) strongly indicated an interaction effect between psychological abuse and affective inhibitory control in girls, suggesting that affective inhibitory control moderates the relationship between psychological abuse and internalizing problems in female adolescents. We investigated this interaction further by conducting a simple slopes analysis in order to test the conditional effects of psychological abuse on internalizing problems at three different levels of affective inhibitory control (i.e., 10 percent, 18 percent, and 30 percent commission errors). 
As shown in Table 3, psychological abuse predicts internalizing problems at all three levels of affective inhibitory control problems.

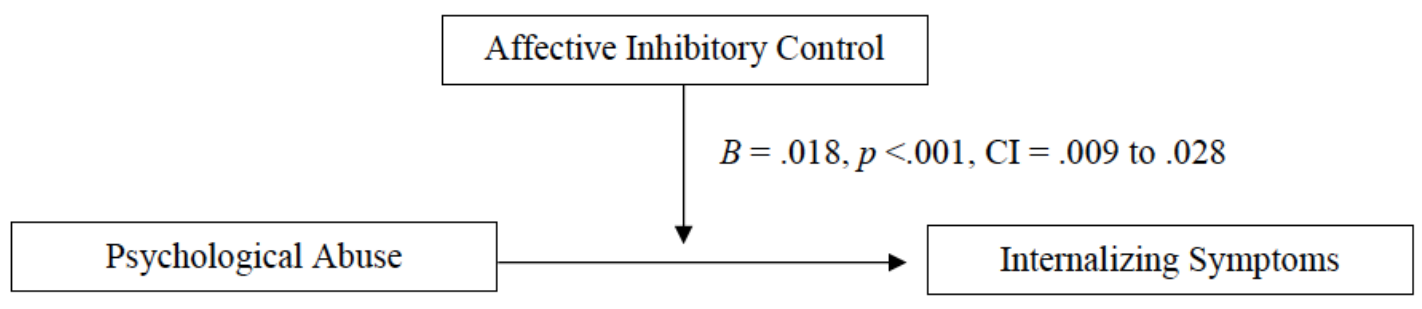

Figure 2. Moderation by Affective Inhibitory Control in the Relationship between Psychological Child Maltreatment and Internalizing Problems in Female Adolescents.

Table 3. Simple slope investigation of the interaction effect showing effects at low, moderate and high rates of inhibition errors.

\begin{tabular}{llccc}
\hline FA Angry & $B$ & $p$ & \multicolumn{2}{c}{$95 \% \mathrm{CI}$} \\
\hline 10 percent & .351 & $<.001$ & .191 & .512 \\
18 percent & .499 & $<.001$ & .361 & .637 \\
30 percent & .721 & $<.001$ & .522 & .890
\end{tabular}

Note. Higher percent indicates greater error in inhibitory control. Two-tailed 95\% confidence intervals in parentheses. FA Angry = false alarm angry.

We did not find support for an interaction between psychological child maltreatment and affective inhibitory control in boys (FA angry; $B=.003, p<.459, \mathrm{CI}=-.005$ to .010 ), nor for an interaction between physical child maltreatment and FA angry in girls $(B=.009, p<.136$, $\mathrm{CI}=-.003$ to .021$)$ or boys $(B=-.001, p<.822, \mathrm{CI}=-.010$ to .008$)$.

\section{Discussion}

We conducted this study to investigate whether inhibitory control within an emotional context is related to individual variation in abused adolescents' internalizing problems. Our study builds on previous literature on the role of emotion regulatory processes in the development of psychopathology in abused children and adolescents (e.g., Cicchetti, 2016; Dvir et al., 2014; Jennissen et al., 2016; Kim \& Cicchetti, 2010; Peh et al., 2017; Pollak, 2008). However, our study also expands upon this literature by investigating a specific cognitive mechanism important for emotion regulation, namely affective inhibitory control, 
with the use of an objective index in a representative sample of abused adolescents. Overall, our results indicate that affective inhibitory control may be regarded as an individual risk factor for internalizing problems in adolescent girls, and that it is involved in the various individual risks which follow child maltreatment.

In line with our first hypothesis, results indicated that affective inhibitory control was uniquely related to internalizing problems when accounting for the effect of psychological and physical abuse in adolescent girls. This was supported by an increment in the total model's explanation for internalizing problems in girls. In accordance with evidence showing that affective control problems serve as a cognitive vulnerability for internalizing problems in adolescents (Han et al., 2012; Joormann \& Gotlib, 2010; Raes, Verstraeten, Bijttebier, Vasey, \& Dalgleish, 2010; Schweizer, Parker, et al., 2020; Susa et al., 2012; Waters et al., 2009), the current study suggests that this is also true for girls exposed to psychological and physical abuse. The relationship was observed only when angry facial expressions were presented as distractive stimuli, and not when neutral facial expressions were presented as no-go trials. This suggests that the threatening properties of the distractive stimuli explain some of the association that was observed, in line with research showing increased emotional activation in adolescents at risk for depression and anxiety when exposed to fearful or angry facial expressions (Monk et al., 2008). It is also in line with the suggestion that problems with inhibiting responses to threat-related information are a potential etiological cognitive mechanism in the link between child maltreatment and internalizing symptoms (Pollak et al., 2000; Pollak \& Kistler, 2002; Pollak et al., 2009; Pollak \& Sinha, 2002; Schweizer, Parker, et al., 2020; Shackman et al., 2007). However, the same relationship was not observed in boys, which may be explained by the greater risk for internalizing problems in girls compared to boys (Davis et al., 2019; Hayward \& Sanborn, 2002; Zahn-Waxler et al., 2008). The present study expands upon prior literature by exploring these relationships separately in girls and boys.

In line with our second hypothesis, results suggest a moderating effect of affective inhibitory control on the relationship between exposure to psychological child maltreatment and internalizing problems in girls. This finding contributes to current research on the modulating role of emotion regulation in the relationship between exposure to child maltreatment and psychopathology (Cicchetti, 2016; Jennissen et al., 2016; Peh et al., 2017; Pollak, 2008). The moderating effect is in line with Pollak (2008) suggestion that biased attention to threat cues becomes maladaptive when it also involves a failure to regulate, or 
inhibit, attention when faced with such information. Simple slope investigation of the relationship revealed that the interaction effect was observed at low, moderate, and high levels of affective inhibitory control problems in girls. However, as predicted, results suggest that the relationship was substantially stronger for girls who experience greater difficulty inhibiting threatening distractive information. This indicates that the risk of experiencing internalizing problems after exposure to psychological abuse increases alongside affective inhibitory control problems. It is important to note that the results also suggest that girls who inhibit responses to threatening distractive information more efficiently also experience fewer internalizing symptoms. This is in line with previous research showing that adaptive regulation of emotions facilitates resilience in the face of abuse (Kim \& Cicchetti, 2010), and highlights important issues regarding the diversity in individual risk for internalizing problems in abused adolescent girls. The same interaction effect was not observed in the relationship between affective inhibitory control and physical abuse, which is surprising as research has shown a biased attention and hypersensitivity to threat-related cues in physically maltreated children (Pollak, 2008).

Taken together, the results support the hypotheses of this study, but only for girls and only in relation to exposure to psychological child maltreatment. Our results may have been different if we had investigated adolescents with clinical levels of internalizing problems or only those who experienced severe forms of physical and psychological abuse. In addition, the great sample heterogeneity that accompanies the epidemiological nature of the current study may partly explain the small effect sizes in the regression model for adolescent girls and the non-identified relationships within abused male adolescents. Future studies should investigate whether problems with affective inhibitory control are a significant risk factor for externalizing problems in abused male adolescents. This is because boys show higher rates of externalizing behavioral problems, and inhibitory control problems are suggested to be a central regulatory mechanism in this maladaptive behavior in boys (Zahn-Waxler et al., 2008).

\section{Limitations and Future Directions}

This study has a number of notable strengths, such as the large and representative sample, high survey response rate, and the use of an objective behavioral index of affective inhibitory control. Findings should, however, be interpreted in light of some methodological shortcomings. The cross-sectional nature of this study implies that no causal inferences can be made. Prospective data is needed in order to understand the causal nature of this relationship 
(for cohort-profile, see Hafstad et al., forthcoming). Effect sizes were modest and may reflect associations with limited implications for clinical practice. Nevertheless, the large and representative community sample recruited for this study increases the precision (i.e., reduces random error variance) of the included estimates, thus the results should reflect true associations within this population. Consequently, the small but identifiable relationships in the current data may reflect important features of emotion regulatory mechanisms in abused girls that experience internalizing symptoms. This should be investigated further in clinical samples.

Measuring child maltreatment within abused samples is complex and presents several methodological issues. The operationalization of child maltreatment experiences may have led to an underestimation of the degree of severity. Since all items were weighted equally, more severe cases of physical or psychological abuse may have been underestimated, and, in turn, this may have limited the variance within each scale. The present study investigated affective inhibitory control as one of several mechanisms that are crucial for emotion regulation throughout development (Schweizer, Gotlib, et al., 2020; Schweizer, Parker, et al., 2020; Tottenham et al., 2011). It is important to note that emotion regulation is a multifaceted construct that goes beyond affective inhibitory control (Ahmed et al., 2015; Cole, Martin, \& Dennis, 2004; Gross \& Feldman Barrett, 2011; Gyurak, Gross, \& Etkin, 2011). However, we argue that in order to fully understand how emotion regulation relates to child maltreatment and the subsequent risk of psychopathology, it is of great importance to investigate core components of adolescents' emotion regulation (Schweizer, Gotlib, et al., 2020). The emotional Go/No-go task provides the opportunity to measure affective inhibitory control objectively. The task is usually applied in an experimental setting. Within this study, the task was applied in the adolescents' daily classroom setting, which may have provided more ecologically valid results. Nevertheless, external factors, such as classroom noise, may have influenced task performance. In order to reduce the possible confounding influence, all teachers were instructed to place students in a separate quiet classroom. The large sample size will also reduce the influence of random error-variance in the current data. In addition, when comparing the current data with previous validation studies of the emotional Go/No-go task (e.g., Schulz et al., 2007), the mean commission error reported in the present study (FA angry) is within the normative range. This suggests that the quality of the current data from the emotional Go/No-go task is satisfactory. Emotion regulation has the value of being transdiagnostic, and some evidence indicates that cognitive control training increases recruitment of adaptive emotion regulation (Schweizer et al., 2017). Future research should 
investigate whether this is true for abused populations and whether it relates to a reduction in symptom pathology.

\section{Conclusion}

Our findings suggest that a reduced ability to inhibit responses to threatening distractive information relates to increased risk for internalizing symptoms in adolescent girls with a history of psychological and physical abuse. The study also provides new and important insight into how regulatory mechanisms central to emotion regulation help us to understand the great diversity of adaptive and maladaptive responses following child maltreatment. In particular, our study suggests that individual differences in affective inhibitory control moderate the relationship between exposure to psychological abuse and internalizing symptoms in adolescent girls.

\section{References}

Ahmed, S. P., Bittencourt-Hewitt, A., \& Sebastian, C. L. (2015). Neurocognitive bases of emotion regulation development in adolescence. Developmental cognitive neuroscience, 15, 11-25.

Aldao, A. (2012). Emotion regulation strategies as transdiagnostic processes: a closer look at the invariance of their form and function= Estrategias de regulación emocional como procesos transdiagnósticos: una visión más detenida sobre la invarianza de su forma y fun.

Aldao, A., Gee, D. G., De Los Reyes, A., \& Seager, I. (2016). Emotion regulation as a transdiagnostic factor in the development of internalizing and externalizing psychopathology: Current and future directions. Development and psychopathology, 28(4pt1), 927-946.

Aupperle, R. L., Melrose, A. J., Stein, M. B., \& Paulus, M. P. (2012). Executive function and PTSD: Disengaging from trauma. Neuropharmacology, 62(2), 686-694.

Casey, B. (2015). Beyond simple models of self-control to circuit-based accounts of adolescent behavior. Annual review of psychology, 66, 295-319.

Casey, B., Jones, R. M., \& Hare, T. A. (2008). The adolescent brain. Annals of the New York Academy of Sciences, 1124(1), 111-126. 
Casey, B., Tottenham, N., \& Fossella, J. (2002). Clinical, imaging, lesion, and genetic approaches toward a model of cognitive control. Developmental Psychobiology: The Journal of the International Society for Developmental Psychobiology, 40(3), 237254.

Christensen, K. S., Haugen, W., Sirpal, M. K., \& Haavet, O. R. (2015). Diagnosis of depressed young people - criterion validity of WHO-5 and HSCL-6 in Denmark and Norway. Family practice, 32(3), 359-363.

Cicchetti, D. (2016). Socioemotional, personality, and biological development: Illustrations from a multilevel developmental psychopathology perspective on child maltreatment. Annual review of psychology, 67, 187-211.

Cole, P. M., Martin, S. E., \& Dennis, T. A. (2004). Emotion regulation as a scientific construct: Methodological challenges and directions for child development research. Child development, 75(2), 317-333.

Davis, M. M., Miernicki, M. E., Telzer, E. H., \& Rudolph, K. D. (2019). The contribution of childhood negative emotionality and cognitive control to anxiety-linked neural dysregulation of emotion in adolescence. Journal of abnormal child psychology, 47(3), 515-527.

Dvir, Y., Ford, J. D., Hill, M., \& Frazier, J. A. (2014). Childhood maltreatment, emotional dysregulation, and psychiatric comorbidities. Harvard review of psychiatry, 22(3), 149.

Ernst, M. (2014). The triadic model perspective for the study of adolescent motivated behavior. Brain and cognition, 89, 104-111.

Fernandez, K. C., Jazaieri, H., \& Gross, J. J. (2016). Emotion regulation: a transdiagnostic perspective on a new RDoC domain. Cognitive therapy and research, 40(3), 426-440.

Gilbert, R., Widom, C. S., Browne, K., Fergusson, D., Webb, E., \& Janson, S. (2009). Burden and consequences of child maltreatment in high-income countries. The Lancet, 373(9657), 68-81.

Gross, J. J., \& Feldman Barrett, L. (2011). Emotion generation and emotion regulation: One or two depends on your point of view. Emotion review, 3(1), 8-16.

Gyurak, A., Gross, J. J., \& Etkin, A. (2011). Explicit and implicit emotion regulation: a dualprocess framework. Cognition and Emotion, 25(3), 400-412.

Haavet, O. R., Sirpal, M. K., Haugen, W., \& Christensen, K. S. (2010). Diagnosis of depressed young people in primary health care-a validation of HSCL-10. Family practice, $28(2), 233-237$.

Han, G., Klimes-Dougan, B., Jepsen, S., Ballard, K., Nelson, M., Houri, A., . . C Cullen, K. (2012). Selective neurocognitive impairments in adolescents with major depressive disorder. Journal of adolescence, 35(1), 11-20.

Hare, T. A., Tottenham, N., Galvan, A., Voss, H. U., Glover, G. H., \& Casey, B. (2008). Biological substrates of emotional reactivity and regulation in adolescence during an emotional go-nogo task. Biological psychiatry, 63(10), 927-934.

Hayward, C., \& Sanborn, K. (2002). Puberty and the emergence of gender differences in psychopathology. Journal of Adolescent Health, 30(4), 49-58.

Helseforskningsloven. Kapittel 4. Samtykke, §17 C.F.R. (2008).

Hofmann, W., Schmeichel, B. J., \& Baddeley, A. D. J. T. i. c. s. (2012). Executive functions and self-regulation. 16(3), 174-180.

IBM. (2017). IBM Corp. Armonk, NY: IBM Corp.

Jaffee, S. R. (2017). Child maltreatment and risk for psychopathology in childhood and adulthood. Annual review of clinical psychology, 13, 525-551. 
Janson, S. (2001). Barn och misshandel: en rapport om kroppslig bestraffning och annan misshandel i Sverige vid slutet av 1900-talet; rapport utarbetad på uppdrag av Kommittén mot Barnmisshandel: Fritzes.

Janson, S., Långberg, B., \& Svensson, B. (2007). Våld mot barn 2006-2007: En nationell kartläggning.

Jennissen, S., Holl, J., Mai, H., Wolff, S., \& Barnow, S. (2016). Emotion dysregulation mediates the relationship between child maltreatment and psychopathology: A structural equation model. Child abuse \& neglect, 62, 51-62.

Jernbro, C., \& Janson, S. (2017). Våld mot barn 2016. En nationell kartläggning [Violence against children 2016. A national survey]. Stockholm: Stiftelsen Allmänna Barnhuset.

Jernbro, C., Otterman, G., Lucas, S., Tindberg, Y., \& Janson, S. (2017). Disclosure of child physical abuse and perceived adult support among Swedish adolescents. Child abuse review, 26(6), 451-464.

Jernbro, C., Svensson, B., Tindberg, Y., \& Janson, S. (2012). Multiple psychosomatic symptoms can indicate child physical abuse-results from a study of Swedish schoolchildren. Acta paediatrica, 101(3), 324-329.

Joormann, J., \& Gotlib, I. H. (2010). Emotion regulation in depression: relation to cognitive inhibition. Cognition and Emotion, 24(2), 281-298.

Kelley, A. E., Schochet, T., \& Landry, C. F. (2004). Risk taking and novelty seeking in adolescence: introduction to part I. Annals of the New York Academy of Sciences, $1021(1), 27-32$.

Kim, J., \& Cicchetti, D. (2010). Longitudinal pathways linking child maltreatment, emotion regulation, peer relations, and psychopathology. Journal of Child Psychology and Psychiatry, 51(6), 706-716.

Krug, E. G., Mercy, J. A., Dahlberg, L. L., \& Zwi, A. B. (2002). The world report on violence and health. The Lancet, 360(9339), 1083-1088.

Li, M., D'arcy, C., \& Meng, X. (2016). Maltreatment in childhood substantially increases the risk of adult depression and anxiety in prospective cohort studies: systematic review, meta-analysis, and proportional attributable fractions. Psychological medicine, 46(4), 717-730.

Monk, C. S., Telzer, E. H., Mogg, K., Bradley, B. P., Mai, X., Louro, H. M., . . Pine, D. S. (2008). Amygdala and ventrolateral prefrontal cortex activation to masked angry faces in children and adolescents with generalized anxiety disorder. Archives of general psychiatry, 65(5), 568-576.

Mossige, S., \& Stefansen, K. (2007). Vold og overgrep mot barn og unge. Norsk institutt for forskning om oppvekst, velferd og aldring raport, 20.

Mossige, S., \& Stefansen, K. (2016). Vold og overgrep mot barn og unge. Omfang og utviklingstrekk 2007-2015. NOVA rapport, 5, 2016.

Peh, C. X., Shahwan, S., Fauziana, R., Mahesh, M. V., Sambasivam, R., Zhang, Y., . . Subramaniam, M. (2017). Emotion dysregulation as a mechanism linking child maltreatment exposure and self-harm behaviors in adolescents. Child abuse \& neglect, 67, 383-390.

Pollak, S. D. (2008). Mechanisms linking early experience and the emergence of emotions: Illustrations from the study of maltreated children. Current directions in psychological science, 17(6), 370-375.

Pollak, S. D., Cicchetti, D., Hornung, K., \& Reed, A. (2000). Recognizing emotion in faces: developmental effects of child abuse and neglect. Developmental psychology, 36(5), 679. 
Pollak, S. D., \& Kistler, D. J. (2002). Early experience is associated with the development of categorical representations for facial expressions of emotion. Proceedings of the National Academy of Sciences, 99(13), 9072-9076.

Pollak, S. D., Messner, M., Kistler, D. J., \& Cohn, J. F. (2009). Development of perceptual expertise in emotion recognition. Cognition, 110(2), 242-247.

Pollak, S. D., \& Sinha, P. (2002). Effects of early experience on children's recognition of facial displays of emotion. Developmental psychology, 38(5), 784.

R.C.Team. (2019). R: A language and environment for statistical computing. Vienna, Austria. Retrieved from http://www.R-project.org.

Raes, F., Verstraeten, K., Bijttebier, P., Vasey, M. W., \& Dalgleish, T. (2010). Inhibitory control mediates the relationship between depressed mood and overgeneral memory recall in children. Journal of Clinical Child \& Adolescent Psychology, 39(2), 276-281.

Samuelsson, H., Jarnvik, K., Henningsson, H., Andersson, J., \& Carlbring, P. (2012). The Umeå university database of facial expressions: a validation study. Journal of medical Internet research, 14(5).

Schulz, K. P., Fan, J., Magidina, O., Marks, D. J., Hahn, B., \& Halperin, J. M. (2007). Does the emotional go/no-go task really measure behavioral inhibition? Convergence with measures on a non-emotional analog. Archives of Clinical Neuropsychology, 22(2), 151-160.

Schweizer, S., Gotlib, I. H., \& Blakemore, S.-J. (2020). The role of affective control in emotion regulation during adolescence. Emotion, 20(1), 80.

Schweizer, S., Parker, J., Leung, J. T., Griffin, C., \& Blakemore, S.-J. (2020). Age-related differences in affective control and its association with mental health difficulties. Development and psychopathology, 32(1), 329-341.

Schweizer, S., Samimi, Z., Hasani, J., Moradi, A., Mirdoraghi, F., \& Khaleghi, M. (2017). Improving cognitive control in adolescents with post-traumatic stress disorder (PTSD). Behaviour research and therapy, 93, 88-94.

Shackman, J. E., Shackman, A. J., \& Pollak, S. D. (2007). Physical abuse amplifies attention to threat and increases anxiety in children. Emotion, 7(4), 838.

Steinberg, L. (2008). A social neuroscience perspective on adolescent risk-taking. Developmental review, 28(1), 78-106.

Stoltenborgh, M., Bakermans-Kranenburg, M. J., Alink, L. R., \& van IJzendoorn, M. H. (2012). The universality of childhood emotional abuse: a meta-analysis of worldwide prevalence. Journal of Aggression, Maltreatment \& Trauma, 21(8), 870-890.

Strand, B. H., Dalgard, O. S., Tambs, K., \& Rognerud, M. (2003). Measuring the mental health status of the Norwegian population: a comparison of the instruments SCL-25, SCL-10, SCL-5 and MHI-5 (SF-36). Nordic journal of psychiatry, 57(2), 113-118.

Straus, M. A., Hamby, S. L., Finkelhor, D., Moore, D. W., \& Runyan, D. (1998). Identification of child maltreatment with the Parent-Child Conflict Tactics Scales: Development and psychometric data for a national sample of American parents. Child abuse \& neglect, 22(4), 249-270.

Susa, G., Pitică, I., Benga, O., \& Miclea, M. (2012). The self regulatory effect of attentional control in modulating the relationship between attentional biases toward threat and anxiety symptoms in children. Cognition \& emotion, 26(6), 1069-1083.

Sætren, S. S., Sütterlin, S., Lugo, R. G., Makransky, G., \& Prince-Embury, S. (2019). A multilevel investigation of resiliency scales for children and adolescents: the relationships between self-perceived emotion regulation, vagally mediated heart rate variability, and personal factors associated with resilience. Frontiers in psychology, 10, 438. 
Taillieu, T. L., Brownridge, D. A., Sareen, J., \& Afifi, T. O. (2016). Childhood emotional maltreatment and mental disorders: Results from a nationally representative adult sample from the United States. Child abuse \& neglect, 59, 1-12.

Tottenham, N., Hare, T. A., \& Casey, B. (2011). Behavioral assessment of emotion discrimination, emotion regulation, and cognitive control in childhood, adolescence, and adulthood. Frontiers in psychology, 2, 39.

Tottenham, N., Tanaka, J. W., Leon, A. C., McCarry, T., Nurse, M., Hare, T. A., . . Nelson, C. (2009). The NimStim set of facial expressions: judgments from untrained research participants. Psychiatry research, 168(3), 242-249.

Unicef. (1989). Convention on the Rights of the Child.

Vacha-Haase, T., \& Thompson, B. (2004). How to estimate and interpret various effect sizes. Journal of counseling psychology, 51(4), 473.

Wasserstein, R. L., Schirm, A. L., \& Lazar, N. A. (2019). Moving to a World Beyond " $\mathrm{p}<$ $0.05 \%$. In: Taylor \& Francis.

Waters, A. M., Valvoi, J. S. J. J. o. B. T., \& Psychiatry, E. (2009). Attentional bias for emotional faces in paediatric anxiety disorders: An investigation using the emotional go/no go task. 40(2), 306-316.

Yang, Y., Cao, S., Shields, G. S., Teng, Z., \& Liu, Y. (2017). The relationships between rumination and core executive functions: A meta-analysis. Depression and anxiety, 34(1), 37-50.

Zahn-Waxler, C., Shirtcliff, E. A., \& Marceau, K. (2008). Disorders of childhood and adolescence: Gender and psychopathology. Annu. Rev. Clin. Psychol., 4, 275-303. 